\title{
ORAL DOSAGES FORM: MEDICINE CONTAINING CHEWIMG GUM: A REVIEW
}

\author{
Asija Rajesh*, Patel Shreya, Asija Sangeeta \\ Maharishi Arvind Institute of Pharmacy, Department of Pharmaceutics, Mansarovar, Jaipur, Rajasthan, India \\ Email: asijar@gmail.com
}

Received 19 Oct 2012; Review Completed 30 Oct 2012; Accepted 01 Nov 2012, Available online 15 Nov 2012

\begin{abstract}
Chewing gums are mobile drug delivery systems. It is a potentially useful means of administering drugs either locally or systemically via, the oral cavity. Several ingredients are now incorporated in medicated chewing gum, e.g. Fluoride for prophylaxis of dental caries, chlorhexidine as local disinfectant, nicotine for smoking cessation, aspirin as an analgesic, and caffeine as a stay alert preparation. It was concluded that chewing gum is an excellent drug delivery system for selfmedication as it is convenient and can be administered directly without water and they contain one or more active substances which are released by chewing and are intended to be used for local treatment of mouth diseases or systemic delivery after absorption through the buccal mucosa.
\end{abstract}

Key-words: Medicated Chewing Gum, Mouth Diseases, Oral Drug Delivery System.

\section{INTRODUCTION}

Chewing gums are taken orally and oral route of drug delivery is the most preferred route amongst the patient and clinicians due to various advantages it offers, in recent years chewing gums are considered to be friendly oral mucosal drug delivery systems ${ }^{1}$. Chewing gum has been used to deliver therapeutic agents such as nicotine for smoking cessation therapy. A medicated chewing gum is solid, single-dose preparation that is intended to be chewed for a certain period of time, deliver the drug and which may contain one or more than one active pharmaceutical ingredient ${ }^{2}$. Chewing gums are not swallowed and the remaining mass after chewing is discarded. During chewing the drug contained in the gum is released into the saliva. The released drug has got two fates; either it could be absorbed through the oral mucosa or may reach the stomach for GI absorption. In fact both these two fates may occur simultaneously. So, medicated chewing gums offer both local and systemic effect ${ }^{4}$. This drug delivery system offers two absorption pathways. Drug absorbed directly via the buccal membrane avoids metabolism in the gastrointestinal tract and thus the chance of first pass effect of the liver. As a result drug formulation as medicated chewing gum may require reduced dose compared to other oral drug delivery systems ${ }^{5}$.

\section{ADVANTAGES OR DISADVANTAGES ${ }^{6-10}$}

\section{Advantages:}

1. Convenient - promoting higher compliance.

2. Discreet- less stigmatization.

3. Administration without water can be taken anywhere.

4. Excellent for acute medication.

5. Advantageous for patients with difficulty in swallowing tablets.

6. Pleasant taste.

7. Counteracts dry mouth: Through stimulation of the salivary secretion thereby preventing.

8. Candidacies and caries.

9. Highly acceptable by children.
10. The active compounds absorbed at oral level avoid the hepatic circulation and the associated metabolism.

11. The product is rapidly released from the gum after a short period mastication; some absorption takes place by directly through the oral mucosa depending on the active ingredient. Importantly not being swallowed the gum does not reach the stomach. Moreover, the stomach does not suffer from direct contact with high concentrations of active principle, thus reducing the risk of intolerance of the gastric mucosa.

12. The fraction of product reaching the stomach is conveyed by the saliva and delivered continuously and regularly. Active substances are released from medical chewing gum during chewing and are dissolved in saliva. The release rate can be carefully controlled through the formulation of the chewing gum allowing extended exposure in the oral cavity. Active substances that are absorbed through the buccal mucosa pass via the jugular veins directly into the systemic circulation. Due to the rich vascular supply of the buccal mucosa, measurable concentrations of active substances may be in the blood after only a few minutes of chewing and fast onset of action is thus likely to be attained. Furthermore, bioavailability may be increased, as hepatic first pass metabolism and gastrointestinal tract degradation are tract degradation are avoided for buccal-absorbed substances.

13. Consequently, a lower dosage of substance may be therapeutically sufficient, possibly resulting in a fewer side effects, and promote fast absorption. Active substances released from chewing gum are dissolved in saliva when swallowed and are, therefore, readily accessible for absorption in the gastrointestinal tract.

\section{Disadvantages}

1. Risk of over dosage with MCG compared with chewable tablets or lozenges that can be consumed in a considerable.

2. Number and within much shorter period of time. 
3. Sorbitol present in MCG formulation may cause flatulence, diarrhea.

4. Additives in gum like flavouring agent, Cinnamon can cause Ulcers in oral cavity and Licorice cause Hypertension.

5. Chlorhexidine oromucosal application is limited to short term use because of its unpleasant taste and staining properties to teeth and tongue.

6. Chewing gum has been shown to adhere to different degrees to enamel dentures and fillers.

7. Prolong chewing on gum may result in pain in facial muscles and earache in children.

\section{MECHANISM OF DRUG TRANSPORT}

During the chewing process, most of the medications contained within the drug product are released into the saliva and are either absorbed through buccal mucosa or swallowed or absorbed through GIT.

Major pathways of drug transport across buccal mucosa follow simple fickian diffusion. Passive diffusion occurs in accordance without the $\mathrm{pH}$ partition theory. Some carrier mediated transport also observed. Equation for drug flux is:

Where,

$\mathrm{J}=$ drug flux

$\mathrm{D}=$ diffusivity

$\mathrm{Kp}=$ partition coefficient

$\Delta \mathrm{Ce}=$ concentration gradient

$\mathrm{h}=$ diffusional path length

It shows (h) that the flux may be increased by decreasing the diffusional resistance of the membrane by making it more fluid, increasing the solubility of the drug in the saliva immediately adjacent to the epithelium or enhancing the lipophilicity through pro-drug modification. Because of the barrier properties of the tight buccal mucosa, the rate limiting step is the movement of the drug molecules across the epithelium.

Two pathways of permeation across the buccal mucosa are transcellular and paracellular. Permeability coefficient typically ranges from $1 \times 10-5$ to $2 \times 10-10 \mathrm{~cm} / \mathrm{s}$. The pathway of drug transport across oral mucosa may be studied using:

- Microscopic techniques using fluorescent dyes

- Autoradiography and

- Confocal laser scanning microscopic procedures. $\mathrm{J}=\mathrm{DKp} / \Delta \mathrm{Ce}$

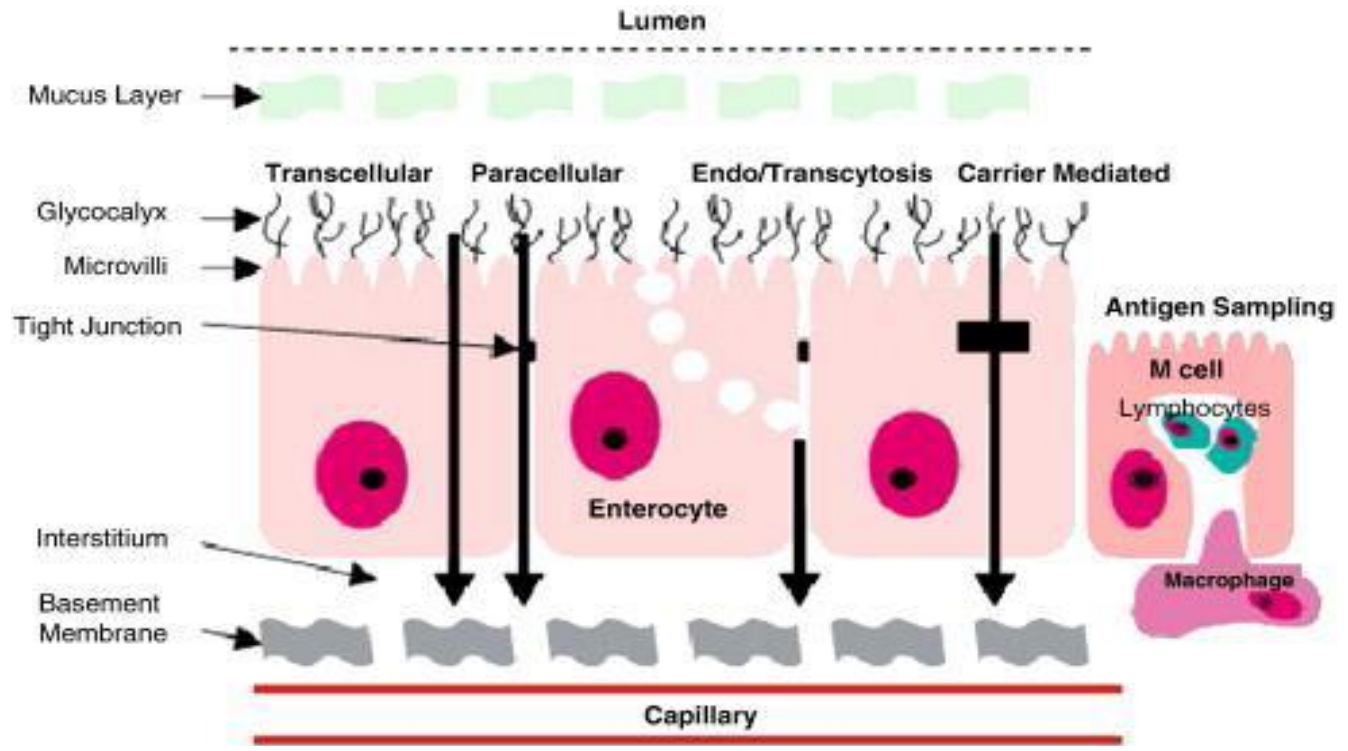

Figure 1: Routes and Mechanisms for Drug Transport across Epithelia ${ }^{9}$

\section{MANUFACTURING PROCEDURE ${ }^{14}$}

Different methods can be employed for the manufacturing of Chewing Gum; however, these can be broadly classified into three main classes namely:

\section{Conventional/ traditional Method (Melting). \\ 2. Cooling, grinding and tabletting Method.}

\section{Direct Compression Method}

\section{Conventional/ traditional Method:}

Components of gum base are softened or melted and placed in a kettle mixer to which sweeteners, syrups, active ingredients and other excipients are added at a definite time. The gum is then sent through a series of rollers that forms into a thin, wide ribbon. During this process, a light coating of finely powdered sugar or sugar substitutes is added to keep the gum away from sticking and to enhance the flavor. In a carefully controlled room, the gum is cooled for upto 48 hours. This allows the gum to set properly. Finally the gum is cut to the desired size and cooled at a carefully controlled temperature and humidity. However, the conventional method has number of limitations like elevated temperature used in melting, restricts the use of this method for thermo labile drugs. Controlling of accuracy and uniformity of drug dose becomes difficult due to melting and mixing of highly viscous gum mass makes. Such a chewing gum composition is difficult to form into chewing gum tablets because of their moisture content (2-8\%). If attempted to grind and tablet such a composition would jam the grinding machine, stick to blades, screens adhere to punches and would be difficult to compress. Technology not so easily adaptable to incorporate the stringent manufacturing conditions required for production of pharmaceutical products ${ }^{12}$. 


\section{COMPOSITION $^{9}$}

Table 1: Represent Composition of medicated chwing gum.

\begin{tabular}{|c|c|c|}
\hline Component & Function & Example \\
\hline \multicolumn{3}{|l|}{$\begin{array}{l}\text { Water insoluble } \\
\text { gum base }\end{array}$} \\
\hline Elastomers & $\begin{array}{l}\text { Provides elasticity and } \\
\text { controls gummy texture }\end{array}$ & $\begin{array}{l}\text { Natural (chicle gum, nispero, rosadinha, jelutong, periollo, } \\
\text { lechi-capsi, sorva etc.) and synthetic rubbers (butadiene, } \\
\text { styrene copolymers, polyisobutylene, polyethylene } \\
\text { mixtures, polyvinyl alcohol etc.) }\end{array}$ \\
\hline $\begin{array}{l}\text { Elastomer } \\
\text { solvents }\end{array}$ & Softening the elastomer base component & $\begin{array}{l}\text { Terpinene resins (polymers of alpha-pinene or beta- } \\
\text { pinene), modified resins or gums (hydrogenated, dimerized } \\
\text { or polymerized resins) }\end{array}$ \\
\hline Plastisizers & $\begin{array}{l}\text { To obtain a variety of desirable textures } \\
\text { and consistency proper-ties }\end{array}$ & $\begin{array}{l}\text { Lanolin, palmitic acid, oleic acid, stearic acid, glyceryl } \\
\text { triacetate, propylene glycol monostearate, glycerine, } \\
\text { natural and synthetic waxes, hydrogenated vegetable oils, } \\
\text { paraffin waxes, fatty waxes, sorbitalmonostearate, } \\
\text { propylene glycol }\end{array}$ \\
\hline $\begin{array}{l}\text { Fillers or } \\
\text { texturizers or } \\
\text { mineral adjuvant }\end{array}$ & $\begin{array}{l}\text { Provide texture, improve chewability, } \\
\text { provide reasonable size of the gum lump } \\
\text { with low dose drug }\end{array}$ & $\begin{array}{l}\text { Calcium carbonate, magnesium carbonate, aluminum } \\
\text { hydroxide, talc, aluminum silicate }\end{array}$ \\
\hline \multicolumn{3}{|l|}{$\begin{array}{l}\text { Water soluble } \\
\text { portions }\end{array}$} \\
\hline $\begin{array}{l}\text { Softners and } \\
\text { emulsifiers }\end{array}$ & $\begin{array}{l}\text { These are added to the chewing gum in } \\
\text { order to optimize the chewability and } \\
\text { mouth feel of the gum }\end{array}$ & $\begin{array}{l}\text { Glycerin, lecithin, tallow, hydrogenated tallow, mono/ di/ } \\
\text { tri glycerides }\end{array}$ \\
\hline $\begin{array}{l}\text { Colorants and } \\
\text { whiteners }\end{array}$ & $\begin{array}{l}\text { Gives the formulation soothing color and } \\
\text { improves acceptability of the formulation }\end{array}$ & $\begin{array}{l}\text { Titanium dioxide, natural food colors and dyes suit-able } \\
\text { for food, drug and cosmetic applications }\end{array}$ \\
\hline Sweeteners & $\begin{array}{l}\text { To provide the desired sweetness of the } \\
\text { product }\end{array}$ & $\begin{array}{l}\text { Water soluble sweetening agents (xylose, ribulose, } \\
\text { glucose, mannose, galactose, sucrose, fructose, mal-tose, } \\
\text { monellin, sugar alcohols like sorbitol, mannitol etc.), water } \\
\text { soluble artificial sweeteners (sodium or calcium saccharin } \\
\text { salts, cyclamate salts etc.), di-peptide based sweeteners } \\
\text { (aspartame, alitame etc.), naturally occurring water soluble } \\
\text { sweeteners, chlo-rinated derivatives of ordinary sugar } \\
\text { (sucralose), protein based sweeteners (thaumatin I and II) }\end{array}$ \\
\hline Antioxidants & Prevents any possible microbial growth & $\begin{array}{l}\text { Butylatedhydroxytoluene, butylatedhydroxyanisole, propyl } \\
\text { gallate }\end{array}$ \\
\hline Flavoring agents & To enhance consumer acceptability & $\begin{array}{l}\text { Essential oils (citrus oil, fruit essences, peppermint oil, } \\
\text { spearmint oil, mint oil, clove oil and oil of wintergreen) } \\
\text { and synthetic or artificial flavors }\end{array}$ \\
\hline Bulking agents & Used if low calorie gum is desired & $\begin{array}{l}\text { Polydextrose, oligofructose, inulin, fructooligosaccharides, } \\
\text { guargumhydrolysate, indigestible dextrin }\end{array}$ \\
\hline $\begin{array}{l}\text { Compression } \\
\text { adjuvant }\end{array}$ & To ease the compression process & Silicon dioxide, magnesium stearate, calcium stearate, talc \\
\hline
\end{tabular}

\section{Cooling, Grinding and Tableting Method:}

This method has been developed with an attempt to lower the moisture content and alleviate the problems faced in conventional method. The Chewing Gum composition (base) is cooled to a temperature at which the composition is sufficiently brittle and would remain brittle during the subsequent grinding step without adhesion to the grinding apparatus. The temperature required for cooling is determined in part by the composition of the Chewing Gum and is easily determined empirically by observing the properties of the cooled chewing gum composition. Generally the temperature of the refrigerated mixture is around $-15 \mathrm{oC}$ or lower. Amongst the various coolants like liquid nitrogen, hydrocarbon slush use of solid carbon dioxide is preferred as it can give temperatures as low as
78.50C. The solid carbon dioxide sublimes readily on warming the mixture and is not absorbed by the chewing gum composition. It does not interact adversely with the processing apparatus and does not leave behind any residue which may be undesirable or potentially hazardous. The refrigerated composition is then crushed or ground to obtain minute fragments of finely ground pieces of the composition. Alternatively, the steps of cooling the chewing gum composition can be combined into a single step. The grinding apparatus itself is cooled by keeping the grinding apparatus in contact with a coolant or by placing the grinding apparatus in a cooling jacket of liquid nitrogen or other cold liquid. For more efficient cooling, the chewing gum composition can be pre cooled prior to cooling to the refrigeration temperature ${ }^{2}$. 
Sometimes a mixture of chewing gum composition, solid carbon dioxide and precipitated silica is ground in a mill grinder in a first grinding step. Additional solid carbon dioxide and silica are added to the ground composition, and the composition is further ground in a second grinding step. This two step grinding process advantageously keeps the chewing gum composition at a very low temperature. The presence of solid carbon dioxide also serves to enhance the efficiency of the grinding process. The same process can be made multiple by incorporating additional carbon dioxide and/or precipitated silica at each step. Certain additives can be added to the chewing gum composition to facilitate cooling, grinding and to achieve desired properties of chewing gum. These include use of anti-caking agent and grinding agent ${ }^{12}$.

Once the coolant has been removed from the powder, the powder can be mixed with other ingredients such as binders, lubricants, coating agents, sweeteners, etc. all of which are compatible with the components of the chewing gum base in a suitable blender such as sigma mill or a high shear mixer.

Alternatively a Fluidized Bed Reactor (FBR) can also be used. The use of FBR is advantageous as it partially rebuilds the powder into granules, as well as coats the powder particles or granules with a coating agent thereby minimizing undesirable particle agglomeration. The granules so obtained can be mixed with anti adherents like talc. The mixture can be blended in a $\mathrm{V}$ type blender, screened \& staged for compression. Compression can be carried out by any conventional process like punching ${ }^{15}$.

Cooling, Grinding and Tabletting Method thus overcomes the limitations of Conventional technique. However, it requires equipment other than conventional tabletting equipment thus making it expensive process as compared to Conventional process. Similar to the Conventional process even this process requires careful monitoring of humidity during the tabletting process.

\section{Direct Compression Chewing Gum:}

SPI pharma has developed a compatible gum system known as Pharmagum. Pharmagum is a mixture of polyols and of sugar with gum base. Pharmagum ${ }^{\circledR} S$ consists primarily of gum base and sorbitol. Pharmagum ${ }^{\circledR} \mathrm{M}$ contains gum base, Mannitol and Isomalt. These are free flowing powders, which are directly compressible. The gum is manufactured under CGMP conditions and complies with food chemicals. Direct compression chewing gum can be directly compressed on a traditional tabletting machine, thus enabling rapid and low cost development of a gum delivery system ${ }^{13}$.

\section{EVALUATION TESTES ${ }^{21}$}

As per specifications given in European Pharmacopoeia:

1) Test for Uniformity of Content: Unless otherwise prescribed or justified and authorized medicated chewing gum with content of $2 \mathrm{mg}$ or less than 2 percent of the total mass of gum comply with test.

2) Uniformity of mass: Uncoated medicated chewing gum and unless otherwise justified and authorized coated medicated chewing gum comply with the test for uniformity of mass of single- dose preparations.
3) Drug release from medicated chewing gum: It has been reported commercially that the drug release from medicated chewing gum as per the specification given in European Pharmacopoeia and is determined by applying a mechanical kneading procedure to a piece of gum placed in a small chewing chamber containing a known volume of buffer solution.

\section{Factor effecting release of drug ingredients}

\section{Contact Time:}

The local or systemic effect is dependent on time of contact of Medicated Chewing Gum in oral cavity. In clinical trial chewing time of 30 minutes was considered close to ordinary use. The average chewing rate is about 60 chews every minute ${ }^{17}$.

\section{Physicochemical properties of active ingredient:}

Physicochemical properties of active ingredient plays very important role in release of drug from Medicated Chewing Gum. The saliva soluble ingredients will be immediately released within few minutes whereas lipid soluble drugs are released first into the gum base and then released slowly. Release of water soluble drug (aqueous solubility greater than 1:10) is, in general, about $75 \%$ or more during $5 \mathrm{~min}$. of chewing and $90 \%$ or more during $15 \mathrm{~min}$. of chewing at rate of 60 chews per minute. Drugs with aqueous solubility between 1:10 and 1:300 demonstrate up to $60 \%$ release during 10 minutes of chewing and between 50 to $90 \%$ when the gum is chewed for $15 \mathrm{~min}$. The release of the drug, which is only slightly water-soluble, can only be expected to be small (less than 5\%) even if the gum is chewed for $30 \mathrm{~min}^{18}$.

\section{Inter individual variability:}

The chewing frequency and chewing intensity which affect the drug release from Medicated Chewing Gum may vary from person to person. In-vitro study prescribed by European Pharmacopoeia suggest 60 cycles per minute chewing rate for proper release of active ingredient ${ }^{19}$.

\section{Formulation factor:}

Composition and amount of gum base affect rate of release of active ingredient. If lipophilic fraction of gum is increased, the release rate is decreased ${ }^{19}$.The influence of gum base mass on drug release has been investigated using salicylamide as model drug. When salicylamide was incorporated into a chewing gum, which contained a relatively large percentage of gum bases, the release after $30 \mathrm{~min}$. of chewing was significantly lower (25.6\%) compared to a gum in which less gum base was present $(52 \%)^{20}$.

\section{APPLICATIONS OF MCGS}

\section{Local therapy:}

Prevention and cure of oral diseases are obvious targets for chewing gum formulations. Chewing gum can release an active substance at a controlled rate over an extended period of time providing a prolonged local effect. Sugarfree chewing gum is known to be beneficial to dental health. It has been shown that use of sugar-free chewing gum after meals re elevates plaque $\mathrm{pH}^{21,22}$. Low plaque $\mathrm{pH}$ plays an important role in the development of dental caries. Therefore, in caries prevention programmes, 
sugar-free chewing gum is recommended after meals and snacks as a supplement to tooth brushing ${ }^{28}$.

Indications for fluoride chewing gum are prevention of dental carries in children in fluoride-deficient areas, in adults with a high incidence of caries, and in patients with xerostomia. The caries-preventive effect of fluoride chewing gum has been compared with the effect of placebo chewing gum in experiments with artificial enamel lesions on teeth mounted into removable mandibular appliances worn in situ in volunteers for several days. The remineralization process proved to be faster when using the fluoride chewing gum.

Oral infections caused by bacteria or fungi are often seen, especially in patients with impaired immune system. Chlorhexidine chewing gum can be used for alleviation of gingivitis, periodontitis, and other oral and pharyngial infections. It can also be used for inhibition of plaque growth and has proven valuable in oral health care of the elderly. Furthermore, chlorhexidine in a chewing gum formulation gives less staining of the teeth and is more convenient to use than a chlorhexidine mouth rinse. The chlorhexidine released by chewing is distributed evenly in the oral cavity and is present there for a prolonged period of time. The bitter taste of chlorhexidine can be masked quite well in a chewing gum formulation Clinical trials involving patients with oral candidosis have shown that miconazole chewing gum is at least as efficient as miconazole oral gel in the treatment of fungal infections in the mouth. Furthermore, patients preferred chewing gum to oral gel due to convenience and fewer side effects. A miconazole chewing gum is yet to be launched ${ }^{29}$.

\section{Systemic Therapy:}

Chewing gum as a drug delivery system also provides benefits to systemic drug delivery, especially if the active substance is absorbed through the buccal mucosa. From a patient point of view, a number of benefits appear: Fast and acute treatment, convenience, no need for water and thereby easy administration anytime anywhere reduced risk of gastrointestinal side effects, and no attention drawn to the condition requiring medication. These benefits apply not only to the treatment of adults, but also to the treatment of children and adolescents. Chewing gum as a drug delivery system could be beneficial to a number of indications, some of which are discussed below $^{30}$.

\section{- Pain:}

Successful treatment of minor pains, headaches, pains of cold, muscular aches, etc. requires rapid absorption of therapeutic doses of the active substance. Chewing gum as a drug delivery system could be beneficial in minor pain treatment, when buccal absorption results in fast onset of action and reduces the risk of gastrointestinal side effects. The bioavailability of acetylsalicylic acid in a chewing gum formulation relative to an unbuffered tablet formulation has been determined. Absorption from the chewing gum formulation was shown to be faster than absorption from the tablet, and consequently, a chewing gum formulation may provide faster pain relief. A chewing gum formulation may also be useful in the treatment of acute, strong pain. Bioavailability of methadone from a chewing gum formulation has been compared to a tablet formulation. There was no significant difference in the bioavailability of the two formulations ${ }^{26}$. The substance abuse problem with methadone tablets could be considerably reduced by formulating methadone in a chewing gum, as the active substance can only be released by chewing ${ }^{29}$.

\section{- Smoking Cessation:}

Chewing gum formulations containing nicotine, lobeline and silver acetate have been clinically tested as aids to smoking cessation. A comparison of success rates and adverse reactions showed that nicotine was superior to the other two substances 27, 28, 29. Several clinical studies have proven the efficacy of nicotine chewing gum as an aid to smoking cessation. Nicotine chewing gum can be regarded as a convenient formulation for breaking an "oral habit" like smoking as the "oral habit" of smoking is substituted by another oral activity, namely gum chewing. The cessation rates observed after one year of treatment vary from $13-63 \%$ in various clinical trials involving nicotine chewing gum, whereas the cessation rate using placebo chewing gum ranges from $9-45 \%$.

\section{- Obesity:}

Several chewing gum formulations containing caffeine, guarana or chromium are available. Caffeine and guarana are central stimulating anorectic agents that have proved to increase the metabolic rate. Moreover, they stimulate lipolysis, have a thermogenic effect (increase energy expenditure) and reduce the feeling of hunger. Chromium is claimed to reduce the craving for food due to an improved blood glucose balance. However, none of the existing products are registered as pharmaceutical products with a documented and approved effect on obesity. Chewing gum has proven efficient in treatments involving instant craving and 'oral habits'. Hence there is a rationale for administering weight reducing active substances in a chewing gum formulation.

\section{Therapeutic Uses of MCGS ${ }^{19}$}

Table 2: Represent Therapeutic uses of Medicated Chewing gum.

\begin{tabular}{|l|l|}
\hline Therapeutic use & Specific example \\
\hline Oral antifungal & $\begin{array}{l}\text { Econazole, Nystatine, } \\
\text { Miconazole }\end{array}$ \\
\hline Smoking cessation & Nicotine, Silver acetate \\
\hline Pain relievers & Aspirin, Methadone \\
\hline $\begin{array}{l}\text { CNS stimulation, } \\
\text { improvement of memory }\end{array}$ & Caffeine \\
\hline Treatment of otitis media & Xylitol \\
\hline Treatment of dental carries & Chlorhexidine \\
\hline $\begin{array}{l}\text { Treatment of vitamin C } \\
\text { deficiency }\end{array}$ & Dimenhydrinate \\
\hline $\begin{array}{l}\text { Treatment and management } \\
\text { of motion sickness }\end{array}$ & Antacid \\
\hline Acid neutralization & Antacid \\
\hline
\end{tabular}




\section{FUTURE TRENDS ${ }^{20,30}$}

Chewing gum not only offers clinical benefits but also is an attractive, discrete and efficient drug delivery system. A few decades ago, the only treatment for some disease was surgical procedure but now more and more disease can be treated with Novel Drug Delivery Systems. Generally, it takes time for a new drug delivery system to establish itself in the market and gain acceptance by patients, however chewing gum is believed to manifest its position as a convenient and advantageous drug delivery system as it meets the high quality standards of pharmaceutical industry and can be formulated to obtain different release profiles of active substances.

The potential of MCG for buccal delivery, fast onset of action and the opportunity for product line extension

\section{REFERENCES}

1. Khatun S, Sutradhar BK, Medicated chewing gum: An unconventional drug delivery system, International Current Pharmaceutical Journal, 2012, 1(4), 86-91.

2. Pagare PK, Satpute CS, Medicated Chewing Gum: A Novel Drug Delivery System, Journal of Applied Pharmaceutical Science, 2012, 02 (06), 40-54.

3. Patel VP, Medicated Chewing gum: A review, International Journal of Universal Pharmacy and Life Sciences, 2011, 1(1), 111-128.

4. Naik H, Gupta S, Medicated chewing gums- updated review: International Journal of Pharma Research and Development, 2011, 2(8), 66-76.

5. Ikam VK, Kotade K, GawareVM, Dolas RT, Medicated chewing gum as a novel drug delivery system - a review, Pharmacologyonline, 2011, 3, 403-413.

6. Patel Y, Shukla A, SainiY, Shrimal N, Sharma P, Chewing gum as a drug delivery system, International Journal of Pharmaceutical Sciences and Research, 2011, 2(4), 748-757.

7. Thombre N, Patel K, A review on medicated chewing gum as a novel drug delivery system, Journal of Pharmacy Research, 2011 , 4(3), 848-851.

8. William PV, Millind T, A Comprehensive Review On: Medicated Chewing Gum, International Journal of Research in Pharmaceutical and Biomedical Sciences, 2012, 3(2), 894-907.

9. Mehta F, Keservani RK, Karthikeyan C, Trivedi P, Chewing gum as a drug delivery system, Arch. Appl. Sci. Res, 2010, 2 (2), 79 99.

10. Mehta F, Trivedi P, Formulation and texture characterization of zein chewing gum, Arch. Appl. Sci. Res., 2012, 4 (2), 781-791.

11. Morjaria Y, Irwin WJ, Barnett PX, Chan RS, Conway BR, In vitro release of nicotine from chewing gum formulations, Dissolution Technologies, 2004, 12-15.

12. Mehta F, Kartikayen C, Trivedi P, "Formulation and characterization of medicated chewing gum delivery of Diphenhydramine Hydrochloride" Der Pharmacia Sinica, 2011, 2 (1), 182-193.

13. Parrott AC, Craig D, Psychological functions served by nicotine chewing gum, Addictive Behaviors, 1995, 20 (3), 271-275.

14. Na D H, Faraj j, Capan Y, Leung KP, Deluca PP, Chewing gum of antimicrobial decapeptide (KSL) as a sustained antiplaque agent: Preformulation study, Jounral of Controlled Release, 2005, 107 (1) $122-130$. makes it an attractive delivery form. Reformulation of an existing product is required for patent protection, additional patient benefits and conservation of revenues.

\section{CONCLUSION}

In the future, we may see drugs formulated into chewing gum in preference to other delivery systems to deliver drugs locally to the oral cavity. The reason is simple that the chewing gum delivery system is convenient, easy to administer anywhere, anytime and its pleasant taste improves patient compliance. Thus, it can be concluded that the chewing gum can be used, as a carrier for vast categories of drugs where extended release and the local action is desired. Chewing gum can be used without water, at any time.
15. Pratik S, Asif K, Ramana MV, Patel M, Kalathaliya M, Chewing Gum: A Modern Era of Drug Delivery, IRJP, 2011, 2(1), 7-12.

16. Gadhavi G, Patel B, Medicated chewing gum a 21st century drug delivery system, 2011, 2(8), 1961-1974.

17. Semwal R, Semwal D, Badoni R, Chewing Gum: A Novel Approach for Drug Delivery, The Journal of Applied Research, 2010, 10(3), 124-131.

18. Imfeld T, Chewing Gum-Facts and Fiction: a Review of gum chewing and oral health, Critical reviews in oral biology \& medicine, 1999, 10(3), 405-419.

19. Hooda R, Tripathi M, Kapoor K, A Review on Oral Mucosal Drug Delivery System, The Pharma Journal, 2012, 1 (1), 13-20.

20. Dong HN, Faraj J, Capan YC, Leung PK, DeLuca P, Chewing gum of antimicrobial decapeptide (KSL) as a sustained antiplaque agent: Preformulation study, Journal of Controlled Release, 2005, 107, 122-130.

21. European Pharmacopoeia. Strasbourg: European Directorate for the Quality of Medicines. Chewing Gums: Medicated, 5th ed., 2004.

22. Pedersen M, Rassing MR, Miconazole chewing gum as a drug delivery system test of release promoting additives, Drug Dev Ind Pharm, 1991, 17 (3), 411-420.

23. Lee WW, Chewing Gum as a delivery vehicle for pharmaceutical and nutraceutical substances, Pharm Tech, 2001, 2, 1-11.

24. Nemeth CR, Benowitz NL, Robinson N, Hennigfield GE, Nicotine gum: chew rate subjective effects and plasma nicotine, Pharmacol Biomed Behav, 1988, 29, 747-751.

25. Michael JR, Jonathan H, Michael SR, Modified- Release Drug Delivery Technology, New York: Marcel Dekker, 2002, 419-429.

26. Ezhumalai K, Medicated chewing gum - a novel drug delivery for systematic and targeted drug delivery system, International Journal of Pharmacy and Technology, 3(1), 2011, 725-744.

27. Amposta R, Medicated chewing gum. Pharma tech, 2011, 22(1), $1-5$.

28. Sharma N, Kaushik D, Dureja H, Medicated chewing gums:A potential drug delivery system, Pharma buzz, 2008, 8(2), 12-13.

29. Yang X, Wang G, Zhang X, Release kinetics of catechins from chewing gum, J Pharm Sci, 2004, 93(2), 293-299.

30. Rassing M, Chewing gum as a drug delivery system, Adv Drug Delivery Rev, 1994, 13, 89-121. 